\title{
Uma revista construída coletivamente
}

\author{
Ajomal bilt collectively
}

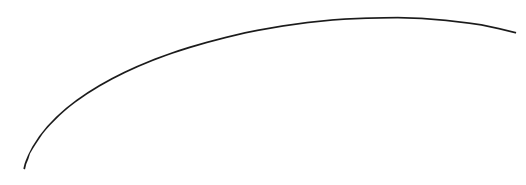

A cada número, os editores se revezam na elaboração do editorial. Sempre que me cabe esta responsabilidade, costumo apresentar um balanço sobre a procedência e a diversidade dos artigos publicados.

Neste número, apresentamos artigos provenientes de instituições de dez diferentes estados brasileiros: Universidade Federal de Alagoas; Universidade Positivo (Paraná); Pontifícia Universidade Católica do Rio Grande do Sul; Universidade Federal do Rio de Janeiro e Universidade Salgado de Oliveira (Rio de Janeiro); Universidade Federal de Pernambuco; Universidade Federal de Mato Grosso; Universidade do Estado de São Paulo e Universidade Sagrado Coração (São Paulo); Universidade Católica de Brasília; e Universidade Federal de Viçosa (Minas Gerais). Há um artigo de revisão proveniente da Unicamp (Campinas-SP) e um estudo de caso que vem da Santa Casa da Misericórdia de Sobral, Ceará.

Além desses textos, nosso editor, Renato Veras, discute em um contundente artigo de opinião as estratégias para o enfrentamento das doenças crônicas, tema que tem sido motivo de grande interesse e polêmica tanto no campo da Saúde Pública quanto no campo da Saúde Suplementar. Portanto, seguimos evoluindo e na vanguarda, tanto em relação ao crescimento da revista quanto no compromisso com a atualização e participação nos debates sobre os temas de maior relevância para a área do envelhecimento.

Este número encerra o décimo-quarto volume da Revista Brasileira de Geriatria e Gerontologia. Em 2011, passamos a ter uma periodicidade trimestral, ou seja, este é o primeiro "quarto número" de um volume da RBGG. Para esta conquista, foi necessário um esforço muito grande do editor principal, das editoras associadas e de toda a equipe do Centro de Referência e Documentação sobre Envelhecimento da UnATI/UERJ. Mas sem a condução firme e segura da nossa editora executiva, não estaríamos realizando mais este projeto.

E sobretudo, queremos agradecer a todos - e são muitos - aqueles que contribuem para a consolidação da RBGG entre as revistas relevantes da área de Geriatria e Gerontologia no Brasil. A melhor forma que encontramos de fazê-lo é celebrar os colaboradores que, com seu esforço anônimo, constituem a espinha dorsal do periodismo científico: os pareceristas. Eles são a primeira e mais importante linha de garantia de qualidade de nossa revista. 
Não podemos deixar de destacar também os financiamentos recebidos das agências de fomento, CNPq e FAPERJ, que viabilizam a produção de nossa revista.

A todos vocês, nosso agradecimento - autores, leitores, conselho editorial, revisores e tantos outros que fazem da $R B G G$ o que ela é.

Desejamos a todos boa leitura e um feliz 2012. 